Center for Policy Impact in Global Health Duke Global Health Institute, Duke University, Durham, NC, USA

gavin.yamey@duke.edu Cite this as: $B M J 2021 ; 372: n 373$ http://dx.doi.org/10.1136/bmj.n373 Published: 10 February 2021

\title{
Developing vaccines for neglected and emerging infectious diseases
}

\author{
Successful development of covid-19 vaccines can provide a blueprint
}

\section{Gavin Yamey professor of global health and public policy}

The rapid development of safe, high efficacy covid-19 vaccines in under a year is one of the greatest scientific achievements in recent history. It has sparked optimism that a vaccine revolution is under way. The success of the covid-19 vaccine enterprise may be transferable to emerging infections and some neglected diseases such as tuberculosis (TB) if the protective antigens are known. ${ }^{1}$

Covid-19 vaccine development has been a spectacular validation of next generation vaccine platforms. ${ }^{2}$ Most vaccines for other diseases were developed using established platforms such as whole inactivated virus (polio vaccine) or live attenuated virus (yellow fever vaccine). By contrast, the covid-19 vaccines with the fastest timelines to phase III efficacy results have used new technologies "best suited for speed" 3 -mRNA and viral vectors. Decades of research went into creating these novel platforms. A recombinant protein approach has also been remarkably fast. 4

Even before the covid-19 pandemic, vaccine companies had started exploring the use of these new technologies for other diseases. Companies are now developing covid-19 mRNA vaccines that help overcome delivery challenges by being thermostable, single dose, or delivered nasally-features that could be valuable in vaccines for other diseases. And since the same production facility can be used to make RNA for different diseases, this should simplify manufacturing. Nevertheless, the chances of success against diseases such as HIV, malaria, and TB are unclear, partly because of the ways in which these pathogens can foil the immune system.

Sixty four covid-19 vaccine candidates are currently in clinical trials and 173 in preclinical development, ${ }^{5}$ a pace of activity made possible by unprecedented financing from an array of funders, including at least \$1obn (€7 bn; €8bn) from the US government. ${ }^{6}$ These huge sums meant that the financial risk was spread among funders. It also meant that preclinical studies, phase I-III trials, and manufacturing of candidates before their approval ("at risk" manufacturing) could happen simultaneously rather than sequentially, accelerating the process and averting delays between development and production. ${ }^{7}$

Cynics would say that rich nations paid up only because of the economic devastation they experienced from covid-19. But having witnessed what is technologically possible with serious financing, research funders may now be motivated to increase funding for developing vaccines against neglected and emerging infections, including funding for at-risk manufacturing. Evidence of generous returns on investments in such development also bolsters the case. ${ }^{8}$
A relatively modest increase in funding could reap large rewards for global health. One modelling study found that even an additional $\$ 1 \mathrm{bn}$ in annual funding for development of vaccines for neglected diseases could greatly increase the odds of launching vaccines against malaria, hepatitis $\mathrm{C}$, and diarrhoeal diseases. ${ }^{9}$

Covid-19 vaccine efforts also benefited from innovations in the governance of vaccine development, such as the 2017 launch of the Coalition for Epidemic Preparedness Innovations (CEPI), a public-private partnership that funds epidemic vaccine development. ${ }^{10} \mathrm{CEPI}$ rapidly pivoted to covid-19 when the pandemic hit. Such new forms of governance should now be replicated in the broader vaccine development landscape. In particular, a new mechanism is urgently needed to aggregate public, philanthropic, and private financing for phase III trials of vaccines against neglected diseases, the costliest phase of development with the lowest chance of success. ${ }^{11}$

Finally, important lessons must be learnt from the successes and failures in supplying covid-19 vaccines globally. Making a vaccine in the laboratory is only the first step: a pathway is also needed to link successful phase III trials with large scale globalised manufacturing, distribution, storage, and delivery. And as we have seen from global covid-19 "vaccine apartheid," ${ }^{12}$ we need to develop allocation systems that are based not just on public health need but on principles of equity and justice.

Competing interests: I have read and understood BMJ policy on declaration of interests and declare I have received research funding from Gavi, the Vaccine Alliance (Gavi), which supports epidemic and pandemic vaccine deployment, and the Bill \& Melinda Gates Foundation, which funds vaccine research and development for neglected and emerging infections. I was a member of the World Bank's COVID-19 Vaccine Development Taskforce and Gavi's working group to develop COVAX. I coauthored a proposal to launch an aggregator for late stage trials of neglected disease product development.

Provenance and peer review: Commissioned; not externally peer reviewed.

Tait DR, Hatherill M, Van Der Meeren O, etal. Final analysis of a trial of M72/AS01E to prevent tuberculosis. N Engl/ Med 2019;381:2429-39. doi: 10.1056/NEJMoa1909953 pmid: 31661198

2 van Riel D, de Wit E. Next-generation vaccine platforms for COVID-19. Nat Mater2020;19:810-2. doi: 10.1038/s41563-020-0746-0 pmid: 32704139

3 Graham BS. Rapid COVID-19 vaccine development. Science 2020;368:945-6. doi: 10.1126/science.abb8923 pmid: 32385100

4 Pollet J, Chen W-H, Strych U. Recombinant protein vaccines, a proven approach against coronavirus pandemics. Adv Drug Deliv Rev 2021:170:71-82.

5 World Health Organization. The COVID-19 vaccine landscape. https://www.who.int/publications/m/item/draft-landscape-of-covid-19candidate-vaccines

6 Branswell H, Herper M, Facher L, et al. Operation Warp Speed promised to do the impossible. How far has it come? Stat News 2020 Sep 8. https://www.statnews.com/2020/09/08/operation-warp-speed-promisedto-do-the-impossible-how-far-has-it-come/

Gupta R. Advancing new tools for infectious diseases. Science 2020;370:913-4. doi: 10.1126/science.abe0773 pmid: 33214267 
8 Summers LH, Yamey G. The world's new health goal will need game-changing technologies. Huffington Post 2015 Sep 3. https://www.huffpost.com/entry/the-worlds-new-health-goal-willneed-game-changing-technologies_b_8060142

9 Bandara S, Chapman N, Chowdhary V, etal. Analysis of the health product pipeline for poverty-related and neglected diseases using the Portfolio-to-Impact (P2I) modeling tool. F1000 Res 2020;9:416. doi: 10.12688/f1000research.24015.1.

10 Coalition for Epidemic Preparedness Innovations https://cepinet/

11 Yamey G, Schäferhoff M, Moran M, et al. Developing an aggregator mechanism for late-stage clinical trials of neglected disease product candidates. Duke Global Working Paper Series № 23. 2020. https://papers.ssrn.com/sol3/papers.cfm?abstract_id=3711578

12 Byanyima W. A global vaccine apartheid is unfolding. People's lives must come before profit. Guardian 2021 Jan 29. https://www.theguardian.com/global-development/2021/jan/29/a-globalvaccine-apartheid-is-unfolding-peoples-lives-must-come-before-profit 